\title{
Does the PPARA Intron 7 Gene Variant (rs4253778) Influence Performance in Power/Strength-Oriented Athletes? A Case-Control Replication Study in three Cohorts of European Gymnasts
}

\author{
by \\ Agnieszka Maciejewska-Skrendo ${ }^{1,3}$, Jan Mieszkowski ${ }^{1}$, Andrzej Kochanowicz, \\ Bartosz Niespodziński², Paweł Cieszczyk ${ }^{1}$ Katarzyna Leźnicka1, \\ Agata Leońska-Duniec ${ }^{1}$, Marek Kolbowicz ${ }^{3}$, Mariusz Kaczmarczyk1, \\ Elżbieta Piskorska4, Błażej Stankiewicz², Robert Stępniak², Aleksandra Mostowik ${ }^{5}$, \\ Marek Zawartka6,7, Agata Rzeszutko-Bełzowska ${ }^{8}$, Myosotis Massidda ${ }^{9}$, \\ Carla Maria Caló ${ }^{8}$, Egle Kemeryté-Riaubiené ${ }^{10}$, Marek Sawczuk $k^{1,3}$
}

Athletic ability is influenced by several exogenous and endogenous factors including genetic component. Hundreds of gene variants have been proposed as potential genetic markers associated with fitness-related phenotypes as well as elite-level athletic performance. Among others, variants within the PPARA gene that code for the peroxisome proliferator activated receptor $\alpha$ are of potential interest. The main goal of the present study was to determine PPARA $(G / C, r s 4253778)$ genotype distribution among a group of Polish, Lithuanian and Italian international level male gymnasts and to compare our findings with those of previous research on the frequency of the PPARA intron $7 \mathrm{C}$ allele/CC genotype in power/strength-oriented athletes. A total of 464 male subjects (147 gymnasts and 317 controls) from Poland $(n=203)$, Italy $(n=146)$ and Lithuania $(n=107)$ participated in the study. No statistically significant differences were found in any of the analyzed cohorts. However, a significantly higher frequency of the CC genotype of the PPARA rs4253778 polymorphism was observed when all gymnasts were pooled and compared with pooled control using a recessive model of inheritance $(O R=3.33,95 \% C I=1.18-10, p=0.022)$. It is important to know that we investigated a relatively small sample of male European gymnasts and our results are limited only to male participants. Thus, it is necessary to validate our results in larger cohorts of athletes of different ethnicities and also in female gymnasts to find out whether there is a gender effect.

Key words: PPAR $\alpha$, athletic performance, genetic polymorphism, candidate gene.

\footnotetext{
1 - Faculty of Physical Culture, Gdansk University of Physical Education and Sport, Gdansk, Poland.

2 - Institute of Physical Education, Kazimierz Wielki University, Bydgoszcz, Poland.

3 - Institute of Physical Culture Sciences, University of Szczecin, Szczecin, Poland.

4 - Faculty of Pharmacy, Nicolaus Copernicus University Collegium Medicum, Bydgoszcz, Poland.

5 - Institute of Sport Sciences, The Jerzy Kukuczka Academy of Physical Education in Katowice, Poland.

6 - Institute of Entrepreneurship, Jagiellonian University, Kraków, Poland.

7 - Department of Sports and Tourism Management, The Jerzy Kukuczka Academy of Physical Education in Katowice, Poland.

8 - College of Medical Sciences, Institute of Physical Culture Studies, University of Rzeszów, Rzeszów, Poland.

9 - Department of Life and Environmental Sciences, University of Cagliari, Cagliari, Italy.

10 - Vytautas Magnus University, Kaunas, Lithuania.
} 


\section{Introduction}

It is undoubtedly clear that athletic ability is influenced by several exogenous (environmental) factors including nutrition, supplementation, and specialized physical training. Endogenous factors include all components of the human body which are engaged in physical activity such as physique, neuromuscular coordination, immune response, cardiovascular capacity, thermoregulation, water and electrolyte balance, energy metabolism, as well as psychological factors. All of these components are, to a greater or lesser degree, determined by genetic factors (Brutsaert and Parra, 2009; Maciejewska-Skrendo et al., 2019b; Yan et al., 2016). To date, studies of genomic components of traits comprising athletic performance identified hundreds of gene variants as potential genetic markers associated with fitness-related phenotypes as well as elite-level athletic performance (Ahmetov et al., 2016; Moran and Pitsiladis, 2017). Among others, variants within the PPARA gene that code for a peroxisome proliferator activated receptor $\alpha$ (PPAR $\alpha)$, a member of the nuclear steroid hormone receptor superfamily involved in glucose homeostasis and lipid metabolism, have gained attention of researchers (MaciejewskaKarlowska et al., 2013, 2014; MaciejewskaSkrendo et al., 2019a; Maciejewska et al., 2011, 2012; Petr et al., 2014, 2018; Zarebska et al., 2014). PPAR $\alpha$ is the key regulator of expression of genes involved in fatty acid metabolism, including fatty acid transport, uptake by the cells, intracellular binding, and activation, as well as catabolism (particularly mitochondrial fatty acid oxidation) or storage. PPAR $\alpha$ is mainly expressed in tissues with elevated mitochondrial and peroxisomal fatty acid oxidation rates, such as a liver, a heart, a kidney, skeletal muscle and brown fat (Desvergne and Wahli, 1999).

Unlike saturated fatty acids which are poor PPAR $\alpha$ ligands, unsaturated fatty acids are the primary natural PPAR $\alpha$ ligands that directly bind to the PPAR $\alpha$ via a ligand binding domain (LBD) and enable to form heterodimers with the nuclear retinoid $X$ receptor (RXR). PPAR:RXR complex binds via the PPAR DNA binding domain (DBD) to the PPRE (peroxisome proliferator response element) sequence within the promoters of the target genes (Kliewer et al.,
1992). PPAR $\alpha$ may also be regulated by insulininduced trans-activation that occurs through the phosphorylation of two mitogen-activated protein (MAP) kinase sites at positions 12 and 21 located in the activation function (AF)-1-like domain within the PPAR $\alpha$ receptor (Juge-Aubry et al., 1999). In humans, the PPARA gene has been mapped to the chromosome 22 and comprises eight exons and seven introns (Sher et al., 1993). Several polymorphic sites have been identified within the PPARA and the single nucleotide polymorphism (SNP) (G/C, rs4253778) localized within the intron 7 of the PPARA has been proposed to play a potential role in response to physical activity. Jamshidi et al. (2002) observed that PPARA rs4253778 polymorphism affected left ventricular growth in response to exercise and hypertension, specifically the CC ang CG individuals had significantly higher left ventricular mass when compared to GG genotype carriers (Jamshidi et al., 2002). Furthermore, the effect of possessing the $\mathrm{C}$ allele was additive: CG heterozygotes had a 2-fold greater, and CC homozygotes had a 3-fold greater increase in left ventricular mass than GG homozygotes. It was proposed that one of the molecular adaptation in the hypertrophied heart was a reduction in PPAR $\alpha$ activity (Barger et al., 2000), an increase in glucose utilization and a decrease in fatty acid oxidation (FAO) (Allard et al., 1994; Sack et al., 1996). Furthermore, it was hypothesized that the PPARA intron $7 \mathrm{C}$ allele impaired PPAR $\alpha$ function and was associated with downregulation of the expression of mitochondrial FAO enzymes, leading to reduced FAO and impaired cellular lipid homeostasis (Jamshidi et al., 2002).

Further studies recruiting athletes that represented different sports disciplines have revealed that it was more likely to find $C$ allele carriers in a group of power-oriented athletes who were involved in short and very intense anaerobic effort (Ahmetov et al., 2006), while GG homozygotes were more prevalent among endurance-type athletes performing predominantly prolonged aerobic exertion (Eynon et al., 2010; Maciejewska et al., 2011). Gineviciene et al. (2010) confirmed the results of previous studies in Lithuanian male athletes showing that those with allele PPARA rs4253778 C had significantly higher muscle mass and better results in explosive strength of lower extremities 
than GG homozygotes (Ginevičienè et al., 2010). Those results were in part explained by the analysis of muscle fiber composition of young men. It was shown that GG homozygotes had a higher percentage of slow-twitch fibers compared to CC homozygotes and the C allele was associated with the propensity to skeletal muscle hypertrophy (Ahmetov et al., 2006).

In view of facts mentioned above, the aim of the present study was to determine PPARA $(\mathrm{G} / \mathrm{C}, \mathrm{rs} 4253778)$ genotype distribution in a group of Polish, Lithuanian and Italian international level male artistic gymnasts and to compare our findings with those of previous research on the frequency of the PPARA intron $7 \mathrm{C}$ allele in power/strength-oriented athletes.

\section{Methods}

\section{Participants}

A total of 464 male subjects (147 gymnasts and 317 controls) from Poland $(n=203)$, Italy $(n=$ 146) and Lithuania $(n=107)$ participated in the study. All gymnasts recruited from Poland, Italy and Lithuania were international athletes defined as those who competed at major international tournaments, while all controls were healthy men without any competitive sport experience. Both gymnasts and controls were self-reported Caucasians for at least 3 generations. Polish participants $(n=203)$ included 58 gymnasts and 145 controls, Italian participants $(n=154)$ included 54 gymnasts and 100 controls, while Lithuanian participants $(n=107)$ included 35 gymnasts and 72 controls.

\section{Ethical approval}

The procedures followed in the study were conducted in accordance with the principles of the World Medical Association Declaration of Helsinki and were approved by the local Ethics Committees (Pomeranian Medical University Ethics Committee, No. BN-001/45/08; Clinical Research at the Regional Chamber in Gdansk, No. KB12/15). All participants were provided with an information sheet concerning study particulars including the purpose of the study and the procedures involved, in addition to the possible risks and benefits associated with participation. All participants provided written informed consent to genotyping with the understanding that it was anonymous and that the obtained results would be confidential. This case-control genetic association study was conducted in accordance with the set of guiding principles for reporting the results of genetic association studies defined by the Strengthening the Reporting of Genetic Association studies (STREGA) Statement (Little et al., 2009).

\section{Genetic analyses}

The buccal cell samples donated by participants were collected in PBS Solution (VWR, USA) with the use of sterile foam-tipped applicators (Puritan, USA). DNA was extracted from the buccal cells using a High Pure PCR Template Preparation Kit (Roche, Switzerland) according to the manufacturer's protocol. Allelic discrimination of the PPARA (G/C, rs4253778) polymorphic site was performed using TaqMan Pre-Designed SNP Genotyping Assays (C__2985251_20, Applied Biosystems, USA), including primers and fluorescently labelled (FAM and VIC) MGB probes for the detection of alleles. All samples were genotyped and visualized with the use of a StepOnePlus real-time polymerase chain reaction (PCR) instrument and StepOne software version 2.2.2 (Applied Biosystems, Foster City, CA, USA). Thermal cycler conditions were as follows: an initial step at $95^{\circ} \mathrm{C}$ for $5 \mathrm{~min}$, followed by 45 cycles of denaturation at $94^{\circ} \mathrm{C}$ for $15 \mathrm{~s}$ and anneal/extend at $60^{\circ} \mathrm{C}$ for $1 \mathrm{~min}$.

\section{Statistical analysis}

All statistical analyses were conducted in the $\mathrm{R}$ programming environment using specific $\mathrm{R}$ packages (version 3.4.0, The $\mathrm{R}$ Foundation for Statistical Computing, https://cran.r-project.org). Genotype and allele frequency distributions, in addition to HWE probabilities, were determined applying different models of inheritance (codominant, dominant, recessive and overdominant) using the SNPassoc package; $p$ values $<0.05$ were considered statistically significant.

\section{Results}

The genotype frequencies in the Polish, Italian and Lithuanian gymnast and control groups as well as the pooled gymnast-control cohorts conformed to the expectations of HardyWeinberg equilibrium (Table 1 ).

Tables 2-4 present the genotype and allele frequency distributions of the PPARA gene variant in the investigated Polish (Table 2), Italian (Table 3) and Lithuanian (Table 4) cohorts. No statistically significant differences were found in 
any of the analyzed cohorts; the genotype distribution amongst the Polish, Italian and Lithuanian cohort of gymnasts was not significantly different from that amongst respective controls when analyzed using the codominant, dominant, recessive and overdominant models (Tables 2-4).
However, significant differences in genotype distribution were observed when all gymnasts from Poland, Italy and Lithuania were pooled and compared with pooled control groups from Poland, Italy and Lithuania using the recessive model of inheritance $(\mathrm{OR}=0.3,95 \% \mathrm{CI}=0.1-0.85$, $p=0.022$; Table 5).

Table 1

Minor allele frequency and Hardy-Weinberg equilibrium probabilities for the PPARA G/C rs4253778 variant in the gymnast and control groups investigated in the recruited Polish, Italian and Lithuanian

\begin{tabular}{|c|c|c|c|c|c|}
\hline \multirow{2}{*}{ Cohort } & \multicolumn{2}{|c|}{ MAF (\% of C) } & \multicolumn{3}{|c|}{ HWE ( $p$ value) } \\
\hline & GYM & $\mathrm{CON}$ & GYM & $\mathrm{CON}$ & $\mathrm{GYM}+\mathrm{CON}$ \\
\hline Polish & 15.5 & 14.8 & 0.108 & 0.435 & 0.818 \\
\hline Italian & 23.1 & 19.0 & 0.397 & 0.692 & 0.783 \\
\hline Lithuanian & 20.0 & 12.5 & 0.526 & 0.893 & 0.644 \\
\hline Total & 19.4 & 15.6 & 0.067 & 0.461 & 0.531 \\
\hline
\end{tabular}

MAF - Minor allele frequency, HWE - Hardy-Weinberg equilibrium, GYM - gymnasts, CON - controls

Table 2

Distribution of PPARA G/C rs4253778 genotypes in gymnasts and controls in the Polish cohort

\begin{tabular}{|c|c|c|c|c|c|c|c|c|}
\hline Modelt & GYM & $\%$ & $\mathrm{CON}$ & $\%$ & OR & \multicolumn{2}{|c|}{$95 \%$ CI } & $p$ \\
\hline \multicolumn{9}{|c|}{ Codominant } \\
\hline G/G & 43 & 74.1 & 104 & 71.7 & 1 & & & \multirow{3}{*}{0.243} \\
\hline $\mathrm{G} / \mathrm{C}$ & 12 & 20.7 & 39 & 26.9 & 0.75 & 0.36 & 1.56 & \\
\hline $\mathrm{C} / \mathrm{C}$ & 3 & 5.2 & 2 & 1.4 & 3.57 & 0.58 & 25.00 & \\
\hline \multicolumn{9}{|c|}{ Dominant } \\
\hline G/G & 43 & 74.1 & 104 & 71.7 & 1 & & & \multirow{2}{*}{0.727} \\
\hline $\mathrm{G} / \mathrm{C}-\mathrm{C} / \mathrm{C}$ & 15 & 25.9 & 41 & 28.3 & 0.88 & 0.44 & 1.75 & \\
\hline \multicolumn{9}{|c|}{ Recessive } \\
\hline G/G-G/C & 55 & 94.8 & 143 & 98.6 & 1 & & & \multirow{2}{*}{0.139} \\
\hline $\mathrm{C} / \mathrm{C}$ & 3 & 5.2 & 2 & 1.4 & 3.85 & 0.63 & 25.00 & \\
\hline \multicolumn{9}{|c|}{ Overdominant } \\
\hline G/G-C/C & 46 & 79.3 & 106 & 73.1 & 1 & & & \multirow{2}{*}{0.351} \\
\hline $\mathrm{G} / \mathrm{C}$ & 12 & 20.7 & 39 & 26.9 & 0.71 & 0.34 & 1.47 & \\
\hline
\end{tabular}


Table 3

Distribution of PPARA G/C rs4253778 genotypes in gymnasts and controls in the Italian cohort

\begin{tabular}{lllllllll}
\hline Modelt & GYM & $\%$ & CON & $\%$ & OR & $95 \%$ CI & $p$ \\
\hline Codominant & 33 & 61.1 & 65 & 65 & 1 & & & \\
G/G & 17 & 31.5 & 32 & 32 & 1.04 & 0.51 & 2.17 & 0.472 \\
G/C & 4 & 7.4 & 3 & 3 & 2.63 & 0.56 & 12.50 & \\
C/C & & & & & & & & \\
Dominant & 33 & 61.1 & 65 & 65 & 1 & & & 0.633 \\
G/G & 21 & 38.9 & 35 & 35 & 1.18 & 0.60 & 2.33 & \\
G/C-C/C & 50 & 92.6 & 97 & 97 & 1 & & & 0.223 \\
Recessive & 4 & 7.4 & 3 & 3 & 2.56 & 0.56 & 12.50 & \\
G/G-G/C & & & & & & & \\
C/C & 37 & 68.5 & 68 & 68 & 1 & & & 0.947 \\
Overdominant & 17 & 31.5 & 32 & 32 & 0.98 & 0.48 & 2.00 & \\
G/G-C/C & & & & & & & \\
G/C & & & & & & & & \\
\hline YM - gymnasts, CON-controls; ${ }^{*}$ p-values; OR-odds ratio, 95\% CI-confidence intervals
\end{tabular}

Table 4

Distribution of PPARA G/C rs4253778 genotypes in gymnasts and controls in the Lithuanian cohort

\begin{tabular}{lllllllll}
\hline Model $\dagger$ & GYM & $\%$ & CON & $\%$ & OR & $95 \%$ CI & $p$ \\
\hline Codominant & & & & & & & & \\
G/G & 23 & 65.7 & 55 & 76.4 & 1 & & & \\
G/C & 10 & 28.6 & 16 & 22.2 & 1.49 & 0.59 & 3.85 & 0.333 \\
C/C & 2 & 5.7 & 1 & 1.4 & 4.76 & 0.41 & 50.00 &
\end{tabular}

Dominant

$\begin{array}{lllllllll}\text { G/G } & 23 & 65.7 & 55 & 76.4 & 1 & & & 0.249 \\ \text { G/C-C/C } & 12 & 34.3 & 17 & 23.6 & 1.69 & 0.69 & 4.17 & \end{array}$

Recessive

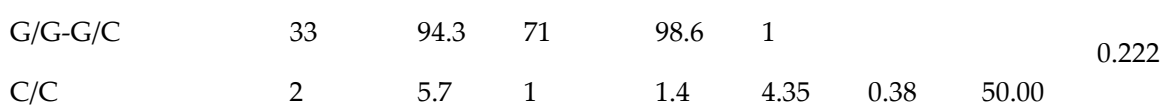

Overdominant

$\begin{array}{lllllll}\text { G/G-C/C } & 25 & 71.4 & 56 & 77.8 & 1 & 0.476\end{array}$

GYM - gymnasts, CON - controls; * p-values; OR - odds ratio, 95\% CI-confidence intervals 


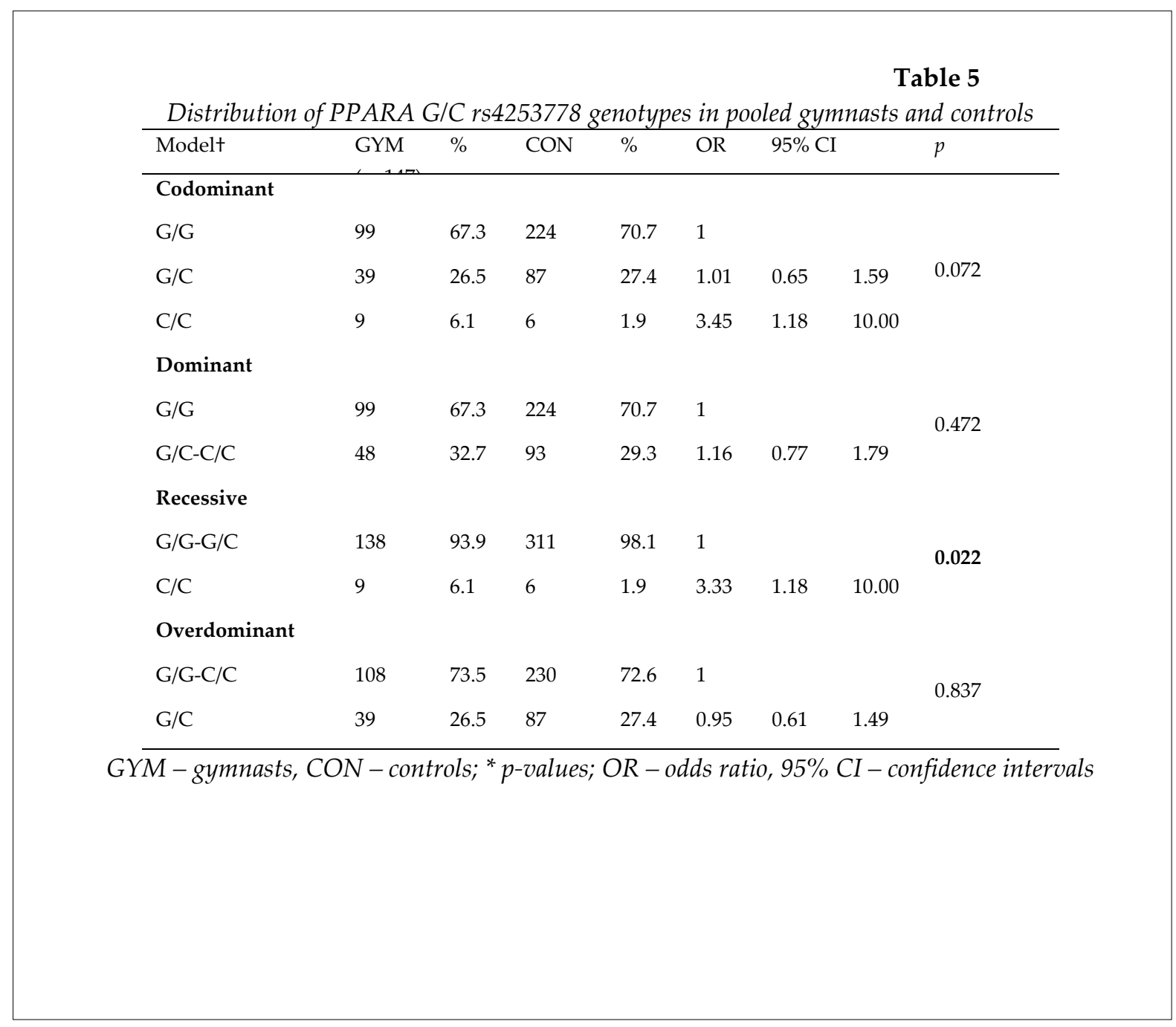

\section{Discussion}

This genetic association study investigated distribution of G/C SNP (rs4253778) located in the intron 7 of the PPARA gene within elite Polish, Italian and Lithuanian gymnasts and non-athletic controls. The main findings of the study were: 1) no significant differences in genotype frequency distributions in the analyzed Polish, Italian and Lithuanian cohorts when tested separately, 2) the over-representation of the CC genotype in the combined group of Polish, Italian and Lithuanian gymnasts compared to the combined control group.

Artistic gymnastics is characterized by performing short routines that range from about 30 up to 90 seconds on different apparatuses. It has been stated that isometric and explosive strength, power speed, strength endurance, as well as dynamic and static flexibility are the most determinant physical fitness aspects of artistic gymnasts (Mkaouer et al., 2018). The intensity and duration of a particular routine determines the contribution primarily from the anaerobic energy system. That is why men's routines such as the pommel horse, floor, parallel bars as well as rings apparatus are disciplines where power/strength is of greater importance than endurance (Morucci et al., 2014).

The results of our research on international level male gymnasts corroborate the previous studies that investigated distribution of intron $7 \mathrm{G} / \mathrm{C}$ SNP (rs4253778) of the PPARA in the recruited athletes and showed that the $\mathrm{C}$ allele or the CC genotype was a candidate for speed/power performance. It has been shown that there was a tendency for power oriented athletes (ie. $60-400 \mathrm{~m}$ runners, $500 \mathrm{~m}$ skaters, $50-100 \mathrm{~m}$ swimmers and weightlifters) to possess the $C$ allele or the CC genotype rather than the GG 
genotype (Ahmetov et al., 2006). The $\mathrm{C}$ allele carriers had also significant hypertrophy of skeletal muscle (due to a higher percentage of fast twitch fibers), what may facilitate glucose utilization in response to anaerobic exercise resulting in higher muscle mass. Finally, it was indicated that PPARA 7C carriers had better results in explosive strength and exhibited higher speed strength measures in the 30-s Wingate Test (WT30) (Ginevičienè et al., 2010; Petr et al., 2014).

In the view of the above, we assumed that CC genotype carriers within the cohort of international artistic gymnasts may possess a metabolic advantage towards anaerobic metabolism. There were several attempts to determine the functional role of the PPARA intron 7 G/C SNP (rs4253778) polymorphism. The 7 intron $C$ allele has been associated with progression of atherosclerosis (Flavell et al., 2002) and was positively correlated with left ventricular growth in response to exercise (Jamshidi et al., 2002). It has been found that reduced $\operatorname{PPAR} \alpha$ activity as well as downregulation of mitochondrial FAO enzymes expression is associated with the hypertrophied heart (Barger et al., 2000; Sack et al., 1996).

Despite the fact that the $7 \mathrm{G} / \mathrm{C}$ polymorphism is located in a noncoding region, it seems to influence the gene's expression probably by linkage disequilibrium with an unidentified functional variant in a promoter or enhancer element within the PPARA regulatory region that the PPARA intron 7 polymorphism may change and disrupt a microRNA site what in consequence alters encoded PPAR $\alpha$ protein levels and may change the PPAR $\alpha$ target genes (Ahmetov et al., 2006; Chen et al., 2010; Cresci et al., 2008).

Therefore, it has been proposed that the intron $7 \mathrm{C}$ allele and $\mathrm{CC}$ genotype involved in the reduction of the PPARA gene expression by downregulating the expression of key metabolic enzymes, may impair the cellular lipid and glucose homeostasis with the elevation of the expression of genes encoding glycolytic enzymes crucial for the anaerobic metabolism (Allard et al., 1994; Maciejewska-Skrendo et al., 2019a).

\section{Acknowledgements}

This work was partly supported by grant N 404166334 founded by polish Ministry of Science and Higher Education.
Moreover, because $\mathrm{C}$ allele carriers are more prone to rely on anaerobic processes what may be an adaptive stimulus leading to muscle fiber transformation, it has also been suggested that the PPARA i7 G/C polymorphism may play an important role in training induced fiber shifts and related muscle metabolism changes (Petr et al., 2014).

We are aware that our study is affected by several limitations. Firstly, as almost every genetic association study, we investigated a relatively small sample of male European artistic gymnasts. We nonetheless tried our best to gain the highest possible number of international level male athletes from Poland, Italy and Lithuania. It is very important to underline, what our results clearly indicate, that a smaller sample size has greater likelihood of not obtaining statistically significant results. It is also important to know that our results are limited only to male participants. Thus, it is necessary to validate our results in larger cohorts of athletes of different ethnicities and also in female gymnasts to find out whether there is a gender effect. Secondly, it is highly probable that variation within the PPARA gene does not affect physiological traits alone. That's why it is important to stress that polymorphic variants of PPARA probably account for only a small portion of phenotypic variability, due to the polygenic character of the traits analyzed, implying that multiple gene-gene as well as gene-environment interactions may contribute to the observed differential effects.

Despite these limitations we believe that our results regarding the intron $7 \mathrm{G} / \mathrm{C}$ SNP of PPARA association with athletic status of highlevel gymnasts may contribute to better understanding whether and how genetic composition of the PPARA gene influences physical performance. We believe that it is quite probable that in near future genetic tests may be applied to identify talented individuals in their respective disciplines as well as to adjust training methods to the genotypic capabilities of athletes. 


\section{References}

Ahmetov II, Egorova ES, Gabdrakhmanova LJ, Fedotovskaya ON. Genes and Athletic Performance: An Update. Med Sport Sci, 2016; 61: 41-54

Ahmetov II, Mozhayskaya IA, Flavell DM, Astratenkova IV, Komkova AI, Lyubaeva EV, Tarakin PP, Shenkman BS, Vdovina AB, Netreba AI, Popov DV, Vinogradova OL, Montgomery HE, Rogozkin VA. PPARalpha gene variation and physical performance in Russian athletes. Eur J Appl Physiol, 2006; 97: 103-8

Allard MF, Schönekess BO, Henning SL, English DR, Lopaschuk GD. Contribution of oxidative metabolism and glycolysis to ATP production in hypertrophied hearts. Am J Physiol, 1994; 267: H742-50

Barger PM, Brandt JM, Leone TC, Weinheimer CJ, Kelly DP. Deactivation of peroxisome proliferatoractivated receptor-alpha during cardiac hypertrophic growth. J Clin Invest, 2000; 105: 1723-30

Brutsaert TD, Parra EJ. Nature versus nurture in determining athletic ability. Med Sport Sci, 2009; 54: 11-27

Chen ES, Mazzotti DR, Furuya TK, Cendoroglo MS, Ramos LR, Araujo LQ, Burbano RR, Smith M de AC. Association of PPARalpha gene polymorphisms and lipid serum levels in a Brazilian elderly population. Exp Mol Pathol, 2010; 88: 197-201

Cresci S, Jones PG, Sucharov CC, Marsh S, Lanfear DE, Garsa A, Courtois M, Weinheimer CJ, Wu J, Province MA, Kelly DP, McLeod HL, Spertus JA. Interaction between PPARA genotype and beta-blocker treatment influences clinical outcomes following acute coronary syndromes. Pharmacogenomics, 2008; 9: 1403-17

Desvergne B, Wahli W. Peroxisome proliferator-activated receptors: nuclear control of metabolism. Endocr Rev, 1999; 20: 649-88

Eynon N, Meckel Y, Sagiv M, Yamin C, Amir R, Sagiv M, Goldhammer E, Duarte JA, Oliveira J. Do PPARGC1A and PPARalpha polymorphisms influence sprint or endurance phenotypes? Scand J Med Sci Sports, 2010; 20: e145-50

Flavell DM, Jamshidi Y, Hawe E, Pineda Torra I, Taskinen M-R, Frick MH, Nieminen MS, Kesäniemi YA, Pasternack A, Staels B, Miller G, Humphries SE, Talmud PJ, Syvänne M. Peroxisome proliferatoractivated receptor alpha gene variants influence progression of coronary atherosclerosis and risk of coronary artery disease. Circulation, 2002; 105: 1440-5

Ginevičienè V, Pranckevičienė E, Milašius K, Kučinskas V. Relating fitness phenotypes to genotypes in Lithuanian elite athletes. Acta medica Litu, 2010; 17: 1-10

Jamshidi Y, Montgomery HE, Hense H-W, Myerson SG, Torra IP, Staels B, World MJ, Doering A, Erdmann J, Hengstenberg C, Humphries SE, Schunkert H, Flavell DM. Peroxisome proliferator--activated receptor alpha gene regulates left ventricular growth in response to exercise and hypertension. Circulation, 2002; 105: 950-5

Juge-Aubry CE, Hammar E, Siegrist-Kaiser C, Pernin A, Takeshita A, Chin WW, Burger AG, Meier CA. Regulation of the transcriptional activity of the peroxisome proliferator-activated receptor alpha by phosphorylation of a ligand-independent trans-activating domain. J Biol Chem, 1999; 274: 10505-10

Kliewer SA, Umesono K, Noonan DJ, Heyman RA, Evans RM. Convergence of 9-cis retinoic acid and peroxisome proliferator signalling pathways through heterodimer formation of their receptors. Nature, 1992; 358: 771-4

Little J, Higgins JPT, Ioannidis JPA, Moher D, Gagnon F, Elm E von, Khoury MJ, Cohen B, Davey-Smith G, Grimshaw J, Scheet P, Gwinn M, Williamson RE, Zou GY, Hutchings K, Johnson CY, Tait V, Wiens M, Golding J, Duijn C van, McLaughlin J, Paterson A, Wells G, Fortier I, Freedman M, Zecevic M, King R, Infante-Rivard C, Stewart A, Birkett N. STrengthening the REporting of Genetic Association Studies (STREGA)--an extension of the STROBE statement. Genet Epidemiol, 2009; 33: 581-98

Maciejewska-Karlowska A, Hanson ED, Sawczuk M, Cieszczyk P, Eynon N. Genomic haplotype within the Peroxisome Proliferator-Activated Receptor Delta (PPARD) gene is associated with elite athletic status. Scand J Med Sci Sports, 2014; 24: e148-55

Maciejewska-Karlowska A, Sawczuk M, Cieszczyk P, Zarebska A, Sawczyn S. Association between the Pro12Ala polymorphism of the peroxisome proliferator-activated receptor gamma gene and strength athlete status. PLoS One, 2013; 8: e67172 
Maciejewska-Skrendo A, Buryta M, Czarny W, Król P, Stastny P, Petr M, Safranow K, Sawczuk M. The Polymorphisms of the Peroxisome-Proliferator Activated Receptors' Alfa Gene Modify the Aerobic Training Induced Changes of Cholesterol and Glucose. J Clin Med, 2019a; 8:

Maciejewska-Skrendo A, Mieszkowski J, Kochanowicz A, Stankiewicz B, Cieszczyk P, Switala K, Gomes de Assis G, Kecler K, Tarnowski M, Sawczuk M. TNFA expression level changes observed in response to the Wingate Anaerobic Test in non-trained and trained individuals. Balt J Heal Phys Act, 2019b; 11: 110

Maciejewska A, Sawczuk M, Cięszczyk P. Variation in the PPAR $\alpha$ gene in Polish rowers. J Sci Med Sport, 2011; 14: 58-64

Maciejewska A, Sawczuk M, Cieszczyk P, Mozhayskaya IA, Ahmetov II. The PPARGC1A gene Gly482Ser in Polish and Russian athletes. J Sports Sci, 2012; 30: 101-113

Mkaouer B, Hammoudi-Nassib S, Amara S, Chaabène H. Evaluating the physical and basic gymnastics skills assessment for talent identification in men's artistic gymnastics proposed by the International Gymnastics Federation. Biol Sport, 2018; 35: 383-392

Moran CN, Pitsiladis YP. Tour de France Champions born or made: where do we take the genetics of performance? J Sports Sci, 2017; 35: 1411-1419

Morucci G, Punzi T, Innocenti G, Gulisano M, Ceroti M, Pacini S. New frontiers in sport training: genetics and artistic gymnastics. J Strength Cond Res, 2014; 28: 459-66

Petr M, Stastny P, Pecha O, Šteffl M, Šeda O, Kohlíková E. PPARA intron polymorphism associated with power performance in 30-s anaerobic Wingate Test. PLoS One, 2014; 9: e107171

Petr M, Stastny P, Zajac A, Tufano JJ, Maciejewska-Skrendo A. The Role of Peroxisome ProliferatorActivated Receptors and Their Transcriptional Coactivators Gene Variations in Human Trainability: A Systematic Review. Int J Mol Sci, 2018; 19(5): 1472

Sack MN, Rader TA, Park S, Bastin J, McCune SA, Kelly DP. Fatty acid oxidation enzyme gene expression is downregulated in the failing heart. Circulation, 1996; 94: 2837-42

Sher T, Yi HF, McBride OW, Gonzalez FJ. cDNA cloning, chromosomal mapping, and functional characterization of the human peroxisome proliferator activated receptor. Biochemistry, 1993; 32: 5598604

Yan X, Papadimitriou I, Lidor R, Eynon N. Nature versus Nurture in Determining Athletic Ability. Med Sport Sci, 2016; 61: 15-28

Zarebska A, Jastrzebski Z, Cieszczyk P, Leonska-Duniec A, Kotarska K, Kaczmarczyk M, Sawczuk M, Maciejewska-Karlowska A. The Pro12Ala polymorphism of the peroxisome proliferator-activated receptor gamma gene modifies the association of physical activity and body mass changes in Polish women. PPAR Res, 2014; 2014: 1-7

\section{Corresponding author:}

\section{Agnieszka Maciejewska-Skrendo}

Unit of Molecular Biology, Department of Health and Natural Sciences,

Faculty of Physical Culture, Gdansk University of Physical Education and Sport

Kazimierza Górskiego 1, 80-336 Gdansk, Poland

E-mail: maciejewska.us@wp.pl 